\title{
Antineonatal Fc Receptor Antibody Treatment Ameliorates MOG-IgG-Associated Experimental Autoimmune Encephalomyelitis
}

Jana Remlinger, MSc,* Adrian Madarasz, MD, * Kirsten Guse, PhD, Robert Hoepner, MD, Maud Bagnoud, PhD, Ivo Meli, MSc, Moritz Feil, MD, Mathias Abegg, MD, PhD, Christopher Linington, PhD, Anthony Shock, PhD, Babak Boroojerdi, MD, PhD, Peter Kiessling, PhD, Bryan Smith, PhD, Volker Enzmann, PhD, Andrew Chan, MD, and Anke Salmen, MD

Neurol Neuroimmunol Neuroinflamm 2022;9:e1134. doi:10.1212/NXI.0000000000001134

\section{Abstract}

\section{Background and Objectives}

Myelin oligodendrocyte glycoprotein antibody-associated disorder (MOGAD) is a rare, autoimmune demyelinating CNS disorder, distinct from multiple sclerosis and neuromyelitis optica spectrum disorder. Characterized by pathogenic immunoglobulin G (IgG) antibodies against MOG, a potential treatment strategy for MOGAD is to reduce circulating IgG levels, e.g., by interference with the IgG recycling pathway mediated by the neonatal Fc receptor $(\mathrm{FcRn})$. Although the optic nerve is often detrimentally involved in MOGAD, the effect of FcRn blockade on the visual pathway has not been assessed. Our objective was to investigate effects of a monoclonal anti-FcRn antibody in murine MOG-IgG-associated experimental autoimmune encephalomyelitis (EAE).

\section{Methods}

We induced active $\mathrm{MOG}_{35-55} \mathrm{EAE}$ in $\mathrm{C} 57 \mathrm{Bl} / 6$ mice followed by the application of a monoclonal MOG-IgG (8-18C5) 10 days postimmunization (dpi). Animals were treated with either a specific monoclonal antibody against FcRn ( $\alpha-F c R n, 4470)$ or an isotype-matched control IgG on 7, 10, and 13 dpi. Neurologic disability was scored daily on a 10-point scale. Visual acuity was assessed by optomotor reflex. Histopathologic hallmarks of disease were assessed in the spinal cord, optic nerve, and retina. Immune cell infiltration was visualized by immunohistochemistry, demyelination by Luxol fast blue staining and complement deposition and number of retinal ganglion cells by immunofluorescence.

\section{Results}

In MOG-IgG-augmented $\mathrm{MOG}_{35-55} \mathrm{EAE}$, anti-FcRn treatment significantly attenuated neurologic disability over the course of disease (mean area under the curve and 95\% confidence intervals (CIs): $\alpha-F c R n ~[n=27], 46.02$ [37.89-54.15]; isotype IgG $[\mathrm{n}=24], 66.75$ [59.54-73.96], 3 independent experiments), correlating with reduced amounts of demyelination and macrophage infiltration into the spinal cord. T- and B-cell infiltration and complement deposition remained unchanged. Compared with isotype, anti-FcRn treatment prevented reduction of visual acuity over the course of disease (median cycles/degree and interquartile range: $\alpha$-FcRn $[\mathrm{n}=16], 0.50$ [0.48-0.55] to $0.50[0.48-0.58]$; isotype $\operatorname{IgG}[\mathrm{n}=17], 0.50[0.49-0.54]$ to $0.45[0.39-0.51])$.
Correspondence

Dr. Salmen

anke.salmen@insel.ch 


\section{Glossary}

abdegs = antibodies that enhance IgG degradation; AUC = area under the curve; AQP4 = aquaporin 4; CCD = charge-coupled device; $\mathbf{c} / \mathbf{d}=$ cycles per degree; $\mathbf{C I}=$ confidence interval; $\mathbf{d p i}=$ days postimmunization; $\mathbf{E A E}=$ experimental autoimmune encephalomyelitis; FcRn = neonatal Fc receptor; $\boldsymbol{\alpha}$-FcRn = specific monoclonal antibody against FcRn; IgG = immunoglobulin G; IF = immunofluorescence; IHC = immunohistochemistry; IP = intraperitoneal; MOG = myelin oligodendrocyte glycoprotein; MOGAD = myelin oligodendrocyte glycoprotein antibody-associated disorder; $\mathbf{M S}=$ multiple sclerosis; NMOSD = neuromyelitis optica spectrum disorder; OMR = optomotor reflex; PFA = paraformaldehyde; $\mathbf{R G C}=$ retinal ganglion cell; ROI = region of interest; $\mathrm{SC}=$ subcutaneous; seldeg $=$ selective degradation.

\section{Discussion}

We show preserved optomotor response and ameliorated course of disease after anti-FcRn treatment in an experimental model using a monoclonal MOG-IgG to mimic MOGAD. Selectively targeting FcRn might represent a promising therapeutic approach in MOGAD.

The development of highly sensitive cell-based assays for the detection of antibodies against myelin oligodendrocyte glycoprotein (MOG) allows to identify a patient subgroup with an inflammatory demyelinating CNS disorder, MOG immunoglobulin G (IgG)-associated disorder (MOGAD). ${ }^{1}$ MOGAD presents with relapsing rather than monophasic neurologic syndromes, most commonly optic neuritis, transverse myelitis, and acute disseminated encephalomyelitis. ${ }^{2,3}$ Although typical criteria for multiple sclerosis (MS) are usually not met, ${ }^{1}$ clinical differentiation of MOGAD and MS may still be difficult. ${ }^{4}$

MOGAD cannot be considered as equivalent to aquaporin 4 (AQP4)-IgG-seronegative neuromyelitis optica spectrum disorder (NMOSD $)^{5}$ due to different epidemiologic, clinical, radiographic features and outcome ${ }^{6}$ and most interestingly remarkable immunologic differences. ${ }^{7-9}$ Retrospective studies suggest that treatment strategies that work well in MS and NMOSD, e.g., targeting CD $20^{+} \mathrm{B}$ cells, are not similarly effective in MOGAD. ${ }^{10,11}$ The intrathecal production of MOG-IgG in a subgroup of patients may contribute to this. ${ }^{9}$ Experimental data indicate the potential limitations of treatment strategies targeting the complement system. ${ }^{8}$ Although there have been several treatment options for AQP4-IgG-seropositive NMOSD recently licensed, ${ }^{12-15}$ evidence-based treatment options are still lacking for MOGAD. ${ }^{16}$

The neonatal $\mathrm{Fc}$ receptor, $\mathrm{FcRn}$, is an important player in $\operatorname{IgG}$ homeostasis. FcRn protects IgG from degradation, thereby prolonging the half-life of IgG in the serum. ${ }^{17}$ After endocytic uptake of IgG from the circulation by endothelial cells and monocytes, FcRn binds IgG in the acidified endosome. This leads to the recycling of IgG back into the circulation, including pathogenic IgG. There are several ways to interfere with the physiologic function of FcRn. Administration of high-dose IVIg has pleiotropic mechanisms of action including the saturation of FcRn and therefore an increased $\operatorname{IgG}$ turnover. ${ }^{18}$ Recombinant antibodies with increased binding affinity for FcRn via their Fc region (antibodies that enhance
IgG degradation, abdegs) outcompete other IgG in experimental models. ${ }^{19,20}$ Engineered MOG-Fc fusion proteins for selective degradation (seldegs) of MOG-specific antibodies have recently been tested in a different experimental model setup. ${ }^{21}$ The $\mathrm{Fc}$ fragment efgartigimod has been investigated in a phase 2 study in immune thrombocytopenia ${ }^{22}$ and in a phase 3 study in myasthenia gravis. ${ }^{23}$

The blockade of FcRn-IgG interaction using high-affinity specific monoclonal antibodies against $\mathrm{FcRn}$ has been proposed as a more direct and selective approach to reduce IgG serum concentration for IgG-mediated autoimmune diseases on the basis of experimental data and first clinical applications. $^{24-28}$ Here, we set out to investigate potential treatment effects of a murine monoclonal anti-FcRn antibody $(\alpha-F c R n)$ in an experimental autoimmune encephalomyelitis (EAE) model enhanced by administration of a monoclonal MOG-IgG.

\section{Methods}

\section{Ethics Approval, Animal Husbandry, and Experimental Planning}

Animal experiments were approved by the governmental authorities of the canton of Bern, Switzerland (BE134/16), and performed in compliance with the ARRIVE guidelines (Animal Research: Reporting of In Vivo Experiments) and Association for Research in Vision and Ophthalmology Statement for the Use of Animals in Ophthalmic and Vision Research. Eight- to 12-week-old female C57Bl/6JRj wild-type mice (Janvier Labs, Le Genest-Saint-Isle, France) were kept under standardized pathogen-free conditions including a stable light/dark cycle (12 hours:12 hours) and access to food and water ad libitum. Experimental procedures were started after an acclimatization period of at least 7 days. Experiments were strictly randomized and analyzed in a blinded manner. Statistical planning assumed an $\alpha$-error of $5 \%$ and 1-statistical power ( $\beta$-error) of $20 \%$. 


\section{Induction of MOG-IgG-Augmented}

\section{MOG $_{35-55}$ EAE}

Chronic EAE was induced by active subcutaneous (SC) immunization with $100 \mu \mathrm{g}$ MOG peptide 35-55 $\left(\mathrm{MOG}_{35-55}\right.$; Charité Berlin, Germany) emulsified in complete Freund's adjuvant under short isoflurane anesthesia. Two hundred nanograms of Pertussis toxin (List Biological Laboratories, Campbell, CA) were injected intraperitoneally (IP) on 0 and 2 days postimmunization (dpi). The experimenters observed the animals after this procedure until they detected normal behavior.

At $10 \mathrm{dpi}$, animals were injected IV with $200 \mu \mathrm{g}$ of murine anti-MOG 8 -18C5 IgG1 $(2 \mathrm{mg} / \mathrm{mL}$, hybridoma cell line provided by Chris Linington, Glasgow, United Kingdom, purified by Aldevron, Freiburg, Germany) or a monoclonal IgG1 isotype (UCB Pharma, Slough, United Kingdom).

\section{Treatment of MOG-IgG-Augmented $M_{35-55}$ EAE}

A monoclonal murine $\alpha$-FcRn IgG1 (4470; UCB Pharma) or monoclonal murine IgG1 isotype control (101.4; UCB Pharma) was administered IP ( $30 \mathrm{mg} / \mathrm{kg}$ body weight $)$ at 7 , 10 , and $13 \mathrm{dpi}$. This dosage and dosing interval were chosen based on previous data with $4470 .^{29}$ Of note, the second day of administration of 4770 coincides with the injection of the 818C5 MOG-IgG but they have different routes of administration (IP and IV, respectively).

\section{Assessments of Disease Course and Visual Function}

\section{Clinical Scoring}

Disease severity was assessed using a 10-point EAE scale: 0, normal; 1, reduced tone of tail; 2, limp tail, impaired righting; 3 , absent righting; 4, gait ataxia; 5 , mild paraparesis of hind limbs; 6, moderate paraparesis; 7, severe paraparesis or paraplegia; 8 , tetraparesis; 9 , moribund; and 10 , death. ${ }^{30-32} \mathrm{~A}$ score of 7 on 3 consecutive days or a score of 8 or higher required early individual termination of the experiment for ethical reasons. As a conservative approach, these animals are continued in the clinical evaluation with the respective last score until 21 dpi (end of experiment for all animals).

\section{Optomotor Reflex Measurement}

As a proxy for visual acuity, optomotor reflex (OMR) was measured in vivo in nonanesthetized, freely moving animals ${ }^{33}$ at baseline (before immunization) and at the end of experiment (19-20 dpi) using a commercially available OMR system (OptoDrum; Striatech, Tübingen, Germany). A rotating black and white striped pattern was presented at a constant velocity of $6.1 \% \mathrm{~s}$ and maximal contrast to animals placed on a platform in the center of 4 computer screens. A chargecoupled device (CCD) camera installed centrally above the platform automatically detected the animal behavior (OMR) in response to the presented stimulus. The software automatically adjusted the stimulating pattern width (in cycles/ degree; staircase assessment). All stimuli were presented and assessed binocularly, and the threshold value per mouse was confirmed in repeated measurements. As the OMR is an autonomous reflex, EAE-related symptoms do not hamper its measurement. ${ }^{34-36}$

\section{Histology, Immunohistochemistry, and Immunofluorescence of the Spinal Cord and Optic Nerve}

Animals were euthanized at $21 \mathrm{dpi}$. Spinal cords and optic nerves were extracted and fixed in $4 \%$ paraformaldehyde (PFA) for 24 hours and embedded in paraffin and 5 - $\mu \mathrm{m}$-thick tissue sections were stained.

Demyelination was assessed after Luxol fast blue (Carl Roth, Arlesheim, Switzerland)/periodic acid-Schiff (VWR International, Dietikon, Switzerland) staining. For immunohistochemistry (IHC), epitopes were unmasked with a Tris-EDTA buffer before blocking with fetal calf serum (Thermo Fisher Scientific, Waltham, MA). IHC was performed for macrophages (rat antimouse Mac3, $0.3 \mu \mathrm{g} / \mathrm{mL}$; BD Pharmingen, Heidelberg, Germany), $\mathrm{T}$ cells (rat anti-human CD3, $10 \mu \mathrm{g} / \mathrm{mL}$; Bio-Rad AbD Serotec, Puchheim, Germany), and B cells (rat anti-mouse B220r, $10 \mu \mathrm{g} / \mathrm{mL}$; Bio-Rad, Cressier, Switzerland) with a biotinylated secondary antibody (biotinylated rabbit anti-rat IgG, $2.5 \mu \mathrm{g} / \mathrm{mL}$; Vector BA, Burlingame, CA) and counterstaining with hematoxylin (VWR International). B-cell staining was only performed in spinal cord tissue due to the sparse infiltration seen therein and limited availability of optic nerve tissue. Complement deposition was visualized by immunofluorescence (IF) staining for C5b-9 (rabbit anti-mouse C5b-9, $10 \mu \mathrm{g} / \mathrm{mL}$; Abcam, Cambridge, United Kingdom).

Images were acquired with a slide scanner (Pannoramic 250 Flash III; 3DHISTECH, Budapest, Hungary) or a Nikon microscope equipped with epifluorescence and CCD camera (Nikon Instruments Europe B.V., Egg, Switzerland) and evaluated using CaseViewer (3DHISTECH) or ImageJ (NIH, Bethesda, MD), respectively.

\section{Retinal Ganglion Cell Count Via Eye Flat Mounts} One eye per animal was fixed in 4\% PFA for 24 hours, and retinal flat mounts were prepared as described before. ${ }^{37}$ After IF staining for retinal ganglion cells (RGCs, goat anti-Brn3a, $0.2 \mu \mathrm{g} / \mathrm{mL}$; Santa Cruz Biotechnology, Dallas, TX), retinas were extended on a microscope slide with the nerve fiber layer facing upward and viewed on a Nikon microscope equipped with epifluorescence. Pictures were taken with a CCD camera (Nikon Instruments Europe B.V.).

\section{Quantification of Tissue Assessments (Spinal Cord, Optic Nerve, and RGCs)}

In transverse spinal cord cross-sections, demyelinated area was determined as percentage of total white matter after manual outlining. Demyelinated area of the optic nerve was assessed with the color deconvolution plugin in ImageJ and expressed as percentage of the complete longitudinal optic nerve section. 
The number of $\mathrm{T}$ cells and macrophages was counted with CaseViewer, and complement fluorescence intensity was quantified with Image $\mathrm{J}$ in 4 regions of interest (ROIs) of 100 $\times 100 \mu \mathrm{m}$ within 2 lesions of the lumbar and thoracic spinal cord each or over the whole optic nerve tissue. B-cell infiltrates were assessed according to a semiquantitative score $(0$, no infiltrate; $1,1-3$ cells; and 2, more than 3 cells or clusters) in 2 sections of the lumbar and thoracic spinal cord, each. RGCs were counted semiautomated in 4 ROIs of $1.11 \mathrm{~mm}^{2}$ around the optic nerve head using ImageJ.

\section{Statistics}

Statistical analysis was performed with GraphPad 9 (GraphPad Software Inc., San Diego, CA). Animal numbers result from 3 pooled independent EAE experiments with the same experimental setup. Varying n-numbers in analyses are due to limited tissue availability or the sole inclusion of animals with available longitudinal OMR measurement, respectively. Data are shown as mean \pm SEM. Unpaired groups were compared using the Mann-Whitney test. For paired groups, the Wilcoxon matchedpairs signed-rank test was used. For the clinical disease course, 95\% confidence intervals (CIs) of the area under the curve (AUC) were additionally calculated to reflect cumulative disease severity. Visual acuity as detected via OMR is given in cycles per degree (c/d) and described in a box-and-whiskers plot with median, interquartile range, and minimum/maximum. The exploratory correlation analyses were performed using Spearman rank correlation, providing Spearman rho $(r)$ and the respective $p$ value.

$p$ Values of $<0.05$ were deemed statistically significant, and levels of significance are indicated as follows: $\mathrm{ns}=$ not significant; ${ }^{*} p<0.05$; ${ }^{* *} p<0.01$; and ${ }^{* * * *} p<0.0001$. Exact $p$ values are given with 2 decimal places, except for $p<0.0001$.

\section{Data Availability}

The data sets supporting the conclusions of this article are available to any qualified researcher on reasonable request.

\section{Results}

\section{Anti-FcRn Treatment Ameliorated Clinical Course of MOG-IgG-Augmented MOG $35-55$ EAE}

A single pilot experiment descriptively depicts the disease course of MOG-IgG-augmented $\mathrm{MOG}_{35-55}$ EAE in our setting compared with EAE using isotype IgG and sham immunization in the presence of MOG or isotype IgG (eFigure 1, links.lww. com/NXI/A688), in line with previous findings. ${ }^{19,38}$ In our model system of MOG-IgG-augmented $\mathrm{MOG}_{35-55}$ EAE, disease incidence in all experiments was $100 \%$ for both groups.

Clinical disease severity was significantly reduced in animals receiving anti-FcRn treatment compared with the isotype IgG-treated group ( $\alpha$-FcRn: $\mathrm{n}=27$; isotype IgG: $\mathrm{n}=24 ; p=$ 0.03 ; Figure 1A). The mean clinical score at the end of experiment was $4.56( \pm 0.33)$ in the anti-FcRn group and 7.04 $( \pm 0.16)$ in the isotype $\operatorname{IgG}$, respectively. The $95 \%$ CIs of the
AUC did not overlap ( $\alpha-F c R n: 37.89-54.15$, mean AUC 46.02; isotype IgG: 59.54-73.96, mean AUC 66.75).

The apparent delay of onset in the anti-FcRn group was caused by 4 animals in the isotype IgG group that developed disease symptoms from $8 \mathrm{dpi}(\mathrm{n}=1)$ and $10 \mathrm{dpi}(\mathrm{n}=3)$ onward, respectively. All other animals developed clinically manifest EAE between 11 and 14 dpi in both groups, i.e., after MOG-IgG administration.

\section{Optomotor Response Was Preserved in Anti-FcRn-Treated Animals}

The OMR revealed no significant differences at baseline in both treatment groups ( $\alpha-\mathrm{FcRn}: 0.50 \mathrm{c} / \mathrm{d}[0.48-0.55], \mathrm{n}=16$; isotype IgG: $0.50 \mathrm{c} / \mathrm{d}$ [0.49-0.54], $\mathrm{n}=17 ; p=\mathrm{ns}$; Figure 1B). Whereas no significant decline was detected in the anti-FcRn group at the end of experiment $(0.50 \mathrm{c} / \mathrm{d}[0.48-0.58] ; p=\mathrm{ns})$, isotype IgG-treated animals displayed a reduction of optomotor response $(0.45 \mathrm{c} / \mathrm{d}[0.39-0.51] ; p=0.02)$.

\section{Morphologic Surrogates Were Supportive of Functional Findings}

Treatment effects on disease course of MOG-IgG-augmented $\mathrm{MOG}_{35-55}$ EAE could be corroborated histologically in the spinal cord (Figure 2) with reduced demyelination (1.8-fold, $p<$ 0.0001 ; Figure 2A) and less macrophage infiltration (1.4-fold, $p$ $<0.0001$; Figure 2B) anti-FcRn-treated animals. No further quantitative differences were detected for $\mathrm{T}$-cell infiltration, B-cell infiltration, or complement deposition (Figure 2, C-E).

Histologic analyses of optic nerve tissue (Figure 3) reflected pathologic involvement in MOG-IgG-augmented $\mathrm{MOG}_{35-55}$ EAE with the presence of demyelination, macrophage infiltration, and complement deposition; yet, no significant differences were detected between the treatment groups (Figure 3, A, B, and D). $\mathrm{T}$-cell counts were increased in animals receiving anti-FcRn treatment (Figure 3C). However, the absolute number of T cells counted in the optic nerves was very low $(\alpha-\mathrm{FcRn}: 3.75$ cells/ROI [0.38], $\mathrm{n}=7$; isotype IgG: 2.07 cells/ROI [0.77], $\mathrm{n}=7, p=0.04$ ). RGC count showed a tendency to be lower in isotype IgG-treated animals ( $\alpha$-FcRn: 2,877 cells/ROI [87.27], $\mathrm{n}=14$; isotype IgG: 2,565 cells/ROI [185.20], $\mathrm{n}=11, p=0.18$, Figure $3 \mathrm{E}$ ).

\section{Correlation of Functional Visual Assessment and Morphology of the Anterior Visual System} In an exploratory analysis, correlation of OMR with optic nerve demyelination and RGC counts was performed (eFigure 2, links.lww.com/NXI/A688). Lower visual acuity correlated with increased optic nerve demyelination $(r=-0.71, p=0.04)$, whereas no significant association was found for OMR and RGC counts $(r=0.16, p=0.45)$.

\section{Discussion}

We here demonstrate a treatment effect of an anti-FcRn antibody on different clinical and morphological outcome 

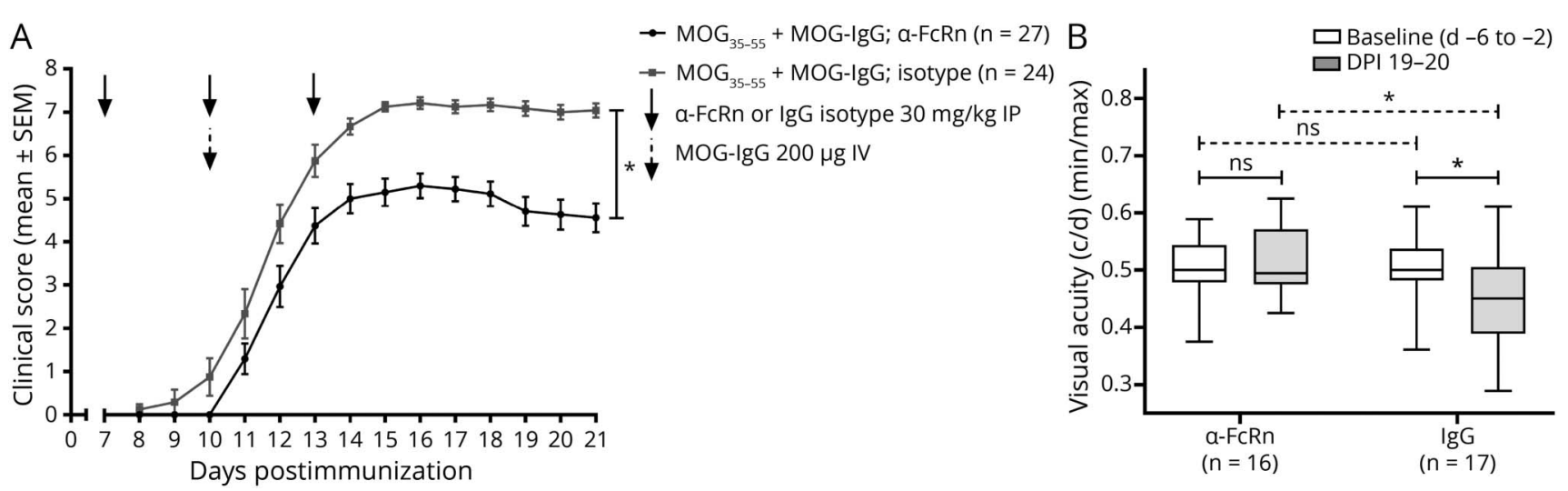

(A) Treatment with anti-FcRn (a-FcRn, black, $\mathrm{n}=27,30 \mathrm{mg} / \mathrm{kg}$, IP) or isotype-matched control antibody (IgG, gray, $\mathrm{n}=24,30 \mathrm{mg} / \mathrm{kg}$, i.p.) on 7, 10, and 13 days postimmunization (dpi). Disease augmentation with MOG-IgG (200 $\mu \mathrm{g}$, IV) on $10 \mathrm{dpi}$. Neurologic disability was scored daily on a $10-$ point scale. $\mathrm{n}=3$ independent experiments, Mann-Whitney test, ${ }^{*} p=0.03$. (B) Visual acuity (c/d) measured as optomotor reflex at baseline (before immunization, days [d] -6 to -2 , white) and at the end of the experiment (19-20 dpi, gray) in anti-FcRn-treated mice (left, $n=16$ paired observations) and in control IgG-treated mice (right, $\mathrm{n}=17$ paired observations), $\mathrm{n}=3$ independent experiments. Within-group comparisons: Wilcoxon signed-rank test, line, ${ }^{\star} p=0.02$ in the control group. Between-group comparisons: Mann-Whitney test, dashed line, ${ }^{\star} p=0.01$ at the end of the experiment, ns $=$ not significant. $\mathrm{c} / \mathrm{d}=\mathrm{cycles}$ per degree; $\mathrm{EAE}=$ experimental autoimmune encephalomyelitis; MOG = myelin oligodendrocyte glycoprotein.

parameters in a murine model of MOG-IgG-augmented $\mathrm{MOG}_{35-55}$ EAE. Histologic correlates in the spinal cord support the reduced severity of disease symptoms. Optomotor response was preserved in anti-FcRn-treated animals as shown by an in vivo automated measurement of spatial visual acuity. In addition, visual acuity correlated with the proportion of demyelination in the optic nerve.

The significance of monoclonal antibodies against MOG (818C5) has been shown experimentally by their potential to exacerbate clinical disease symptoms and demyelination in EAE. ${ }^{19,38}$ Delivery of $8-18$ C5 into the CNS after IV administration, although not reviewed in our setting, was demonstrated before using fluorescence-labeled $8-18 \mathrm{C} 5 .^{19}$ In this context, other IgG-reducing treatment strategies have already been tested. Engineered antibodies that lower endogenous IgG levels by competing for binding to FcRn, the so-called abdegs, or that selectively bind anti-MOG-specific antibodies, seldegs, have shown an effect on the disease course. However, several methodological differences including immunization with a human MOG peptide and later administration of the monoclonal 8-18C5 antibody or polyspecific human IgG from MS patient samples ( 15 vs $10 \mathrm{dpi}$ ) hamper a direct comparison of these models. ${ }^{19-21}$ Abdeg and seldeg have thus far not been used in human settings.

In our model, we applied a specific, high-affinity monoclonal antibody against FcRn (4470) to explore the translatability of a humanized monoclonal antibody (rozanolixizumab) to the treatment of MOGAD. As rozanolixizumab does not bind mouse FcRn, the pharmacologically equivalent murine 4470 antibody was used here. Rozanolixizumab has been evaluated in phase 2 studies in other IgG autoantibody-mediated diseases, myasthenia gravis, and immune thrombocytopenia and has demonstrated promising results. ${ }^{24,26}$ Moreover, a phase 3 clinical study with rozanolixizumab has recently been initiated in patients with MOGAD (NCT05063162).

Lowering of circulating IgG via species-specific anti-FcRn antibodies has been demonstrated before including the murine antibody used in this study. ${ }^{29,39}$ We did not measure the actual decrease of circulating IgG or MOG-IgG in our experiments, representing a limitation of our work.

In addition to the existing data in a model system using an abdeg, ${ }^{19}$ we demonstrate robust morphologic correlates for the spinal disease manifestation. Another important feature of our work is the specific assessment of the visual outcome on a functional and morphological level. We have demonstrated not only the involvement of the optic nerve on a functional level correlating with demyelination but also the effects on visual acuity of an intervention in this system. As a limitation, the morphologic assessments of the optic nerve and retina have been performed with limited animal numbers due to the availability of material. Therefore, further confirmation is required.

Nevertheless, as different visual outcomes including OMR, histology, and optical coherence tomography have just recently been included in experimental models of CNS demyelination, ${ }^{40,41}$ our findings underscore the usefulness of these approaches to perform a multimodal analysis of experimental models and to gain more insights on a potential translation to the human diseases.

To further corroborate our findings measured on a functional level, electrophysiologic outcome parameters might have 

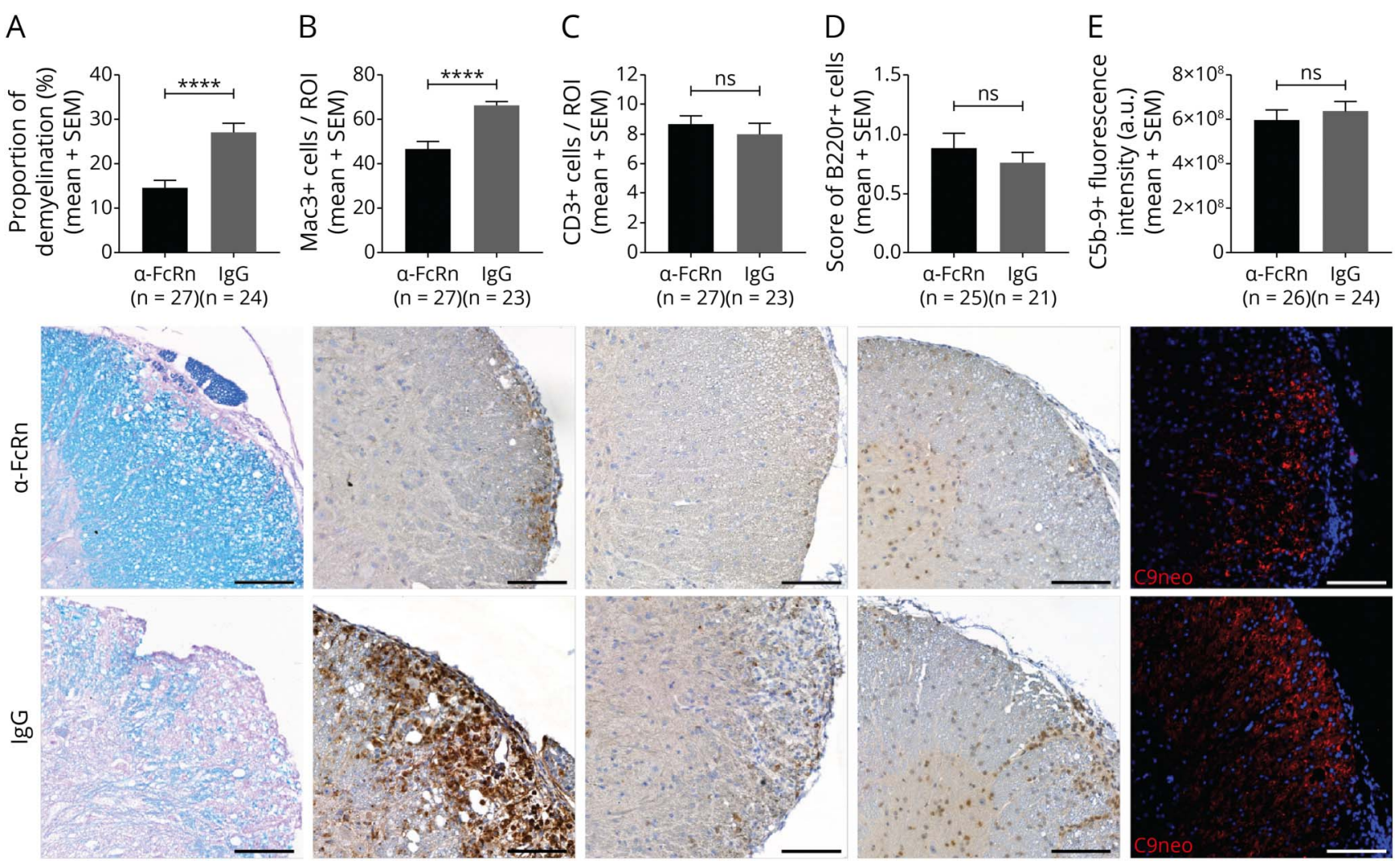

Quantification and histologic representation of the (A) percentage of demyelination after LFB/PAS staining, (B) macrophage infiltration after IHC for Mac3+ cells, (C) T-cell infiltration after IHC for CD3 ${ }^{+}$cells, (D) B-cell infiltration after IHC for B220+ cells, and (E) complement deposition after IF for C5b-9/DAPI in the

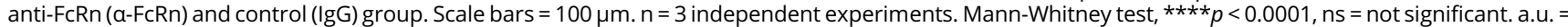
arbitrary units; DAPI = 4',6-diamidino-2-phenylindole; aFcRn = specific monoclonal antibody against FcRn; IF = immunofluorescence; IgG = immunoglobulin G; $\mathrm{IHC}=$ immunohistochemistry; LFB = Luxol fast blue; PAS = periodic acid-Schiff; ROI = region of interest.

been included. Yet, differences were already detectable using the noninvasive OMR measurement. Thus, the gain of additional insight in the visual system by measuring the more sensitive visual evoked potentials with an implanted electrode would be limited. ${ }^{42}$

To detect retinal involvement in EAE, different model systems and methodology have been used. Thereby, retinal degeneration has already been demonstrated..$^{40,41,43}$ Lacking a functional outcome, RGC loss at 23 dpi has been detected with Brn3a staining. ${ }^{43}$ With neuronal nuclei (NEUN) and apoptosis (TUNEL) staining, retinal neuron loss has been gradually found from $11 \mathrm{dpi}$ on in a $\mathrm{MOG}_{35-55}$ EAE model reaching its maximum at $28 \mathrm{dpi}^{41}$ Comparing different EAE models, RGC loss detected via Brn3a and beta-III-tubulin staining has been shown as a long-term outcome ( 120 days up to 9 months after immunization), yet with considerable variance in some of the model systems. ${ }^{40}$ All these studies compared different EAE mice with controls and were not directly comparable to our setting.

Thus, the lack of a significant difference in RGC at 21 dpi in our setup comparing anti-FcRn-treated and control mice could be explained (1) by the comparatively early time point of assessment, (2) high interindividual variance of total RGC counts, or (3) smaller differences between 2 diseased groups.

The assumption is that the anti-FcRn demonstrated efficacy in our model by removing pathogenic anti-MOG antibodies. However, because $\mathrm{FcRn}$ is also known to be involved in modulating immune complex presentation in antigenpresenting cells and subsequent activation of $\mathrm{T}$ cells, ${ }^{44}$ one could hypothesize that modulation of the primarily $\mathrm{T}$ celldriven $\mathrm{MOG}_{35-55}$ EAE response ${ }^{45}$ was also involved. In our setup, this has not been investigated in more detail.

A potential limitation in the translation of our study to a human setting may be the timing of anti-FcRn application before the administration of MOG-IgG. However, it was applied after the active peptide immunization phase, creating an inflammatory CNS background so that our setup is not a prophylactic treatment in sensu stricto.

In an experimental model using a monoclonal MOG-IgG to mimic MOGAD, treatment with a specific monoclonal antibody against $\mathrm{FcRn}$ has demonstrated positive effects on spinal 

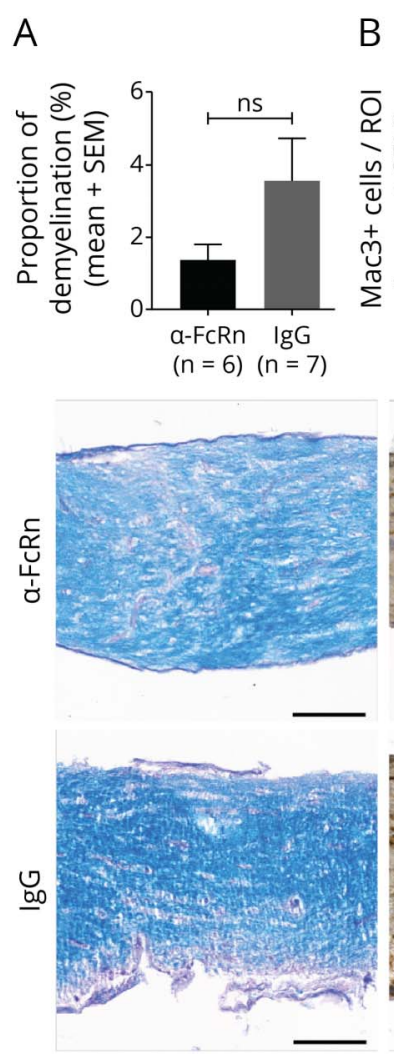

B
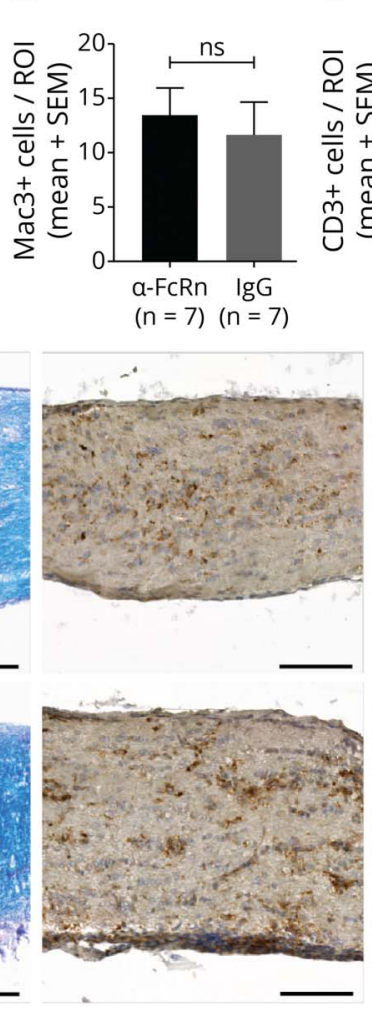

C
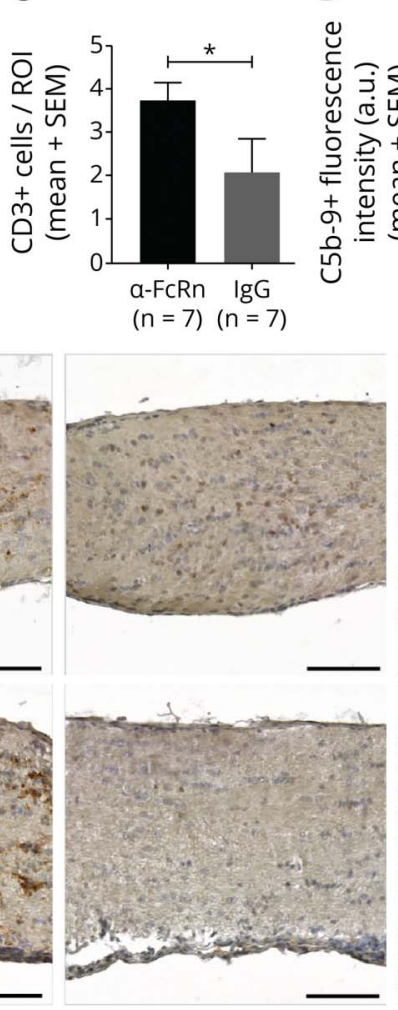
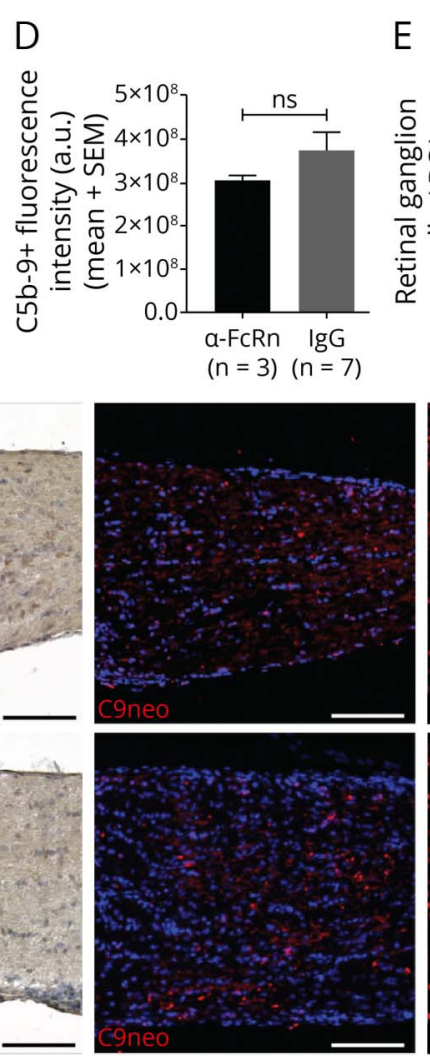

$\mathrm{E}$
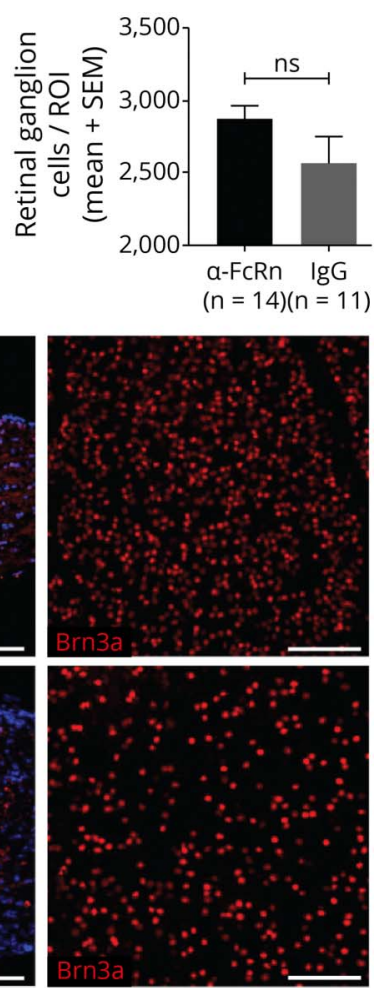

Quantification and histologic representation of the (A) percentage of demyelination after LFB/PAS staining, (B) macrophage infiltration after IHC for Mac3+ cells, (C) T-cell infiltration after IHC for $\mathrm{CD}^{+}$cells, (D) complement deposition after IF for C5b-9/DAPI, and (E) retinal ganglion cells counted on retinal flat mount with IF for Brn3a+ in the anti-FcRn ( $\mathrm{a}-\mathrm{FcRn})$ and control (IgG) group. Scale bars $=100 \mu \mathrm{m} . \mathrm{n}=2$ independent experiments. Mann-Whitney test, ${ }^{*} p=0.04$, ns $=$ not significant. a.u. = arbitrary units; DAPI = 4',6-diamidino-2-phenylindole; $a F c R n=$ specific monoclonal antibody against FcRn; IF = immunofluorescence; IgG = immunoglobulin G; IHC = immunohistochemistry; LFB = Luxol fast blue; PAS = periodic acid-Schiff; ROI = region of interest.

cord and optic nerve manifestations that represent the most common and disabling symptoms in MOGAD. If these effects were further corroborated and translated into the human situation, anti-FcRn therapy could become a promising treatment option in a disease, which thus far lacks evidencebased therapeutics.

\section{Acknowledgment}

The authors thank Dr. L. Thiele for the critical discussions and V. Bösiger and E.C. De Oliveira Figueiredo for assistance in the histological workflow.

\section{Study Funding}

This project was funded by UCB Pharma, Slough, United Kingdom. UCB provided material (antibodies as given in the manuscript) and financial support. They were not involved in the collection and analysis of data. They supported the design of experiments (dosing schedule) and interpretation of data (prophylactic vs therapeutic dosing). They revised the manuscript for intellectual content and approved the final version.

\section{Disclosure}

J. Remlinger and A. Madarasz report no disclosures relevant to the manuscript. K. Guse is a former employee of Biogen, not related to this study. R. Hoepner received speaker/advisor honorary from Merck, Novartis, Roche, Biogen, Alexion, Sanofi, Bristol-Myers Squibb, and Almirall; he received research support within the last 5 years from Roche, Merck, Sanofi, Biogen, and Bristol-Myers Squibb; he also received research grants from the Swiss MS Society. M. Bagnoud, I. Meli, M. Feil, M. Abegg, and C. Linington report no disclosures relevant to the manuscript. A. Shock, B. Boroojerdi, and P. Kiessling, and B. Smith are employees of UCB Pharma. V. Enzmann reports no disclosures relevant to the manuscript. A. Chan has received speakers'/board honoraria from Actelion (Janssen/J\&J), Almirall, Bayer, Biogen, Celgene (BMS), Genzyme, Merck KGaA (Darmstadt, Germany), Novartis, Roche, and Teva, all for hospital research funds; he received research support from Biogen, Genzyme, and UCB, the European Union, and the Swiss National Foundation; he serves as associate editor of the European Journal of Neurology, on the editorial board for Clinical and Translational Neuroscience, and as topic editor for the Journal of International Medical Research. A. Salmen received speaker honoraria and/or travel compensation for activities with Almirall Hermal GmbH, Biogen, Merck, Novartis, Roche, and Sanofi Genzyme and research support by the Baasch Medicus Foundation and the Swiss MS Society. Go to Neurology.org/NN for full disclosures. 


\section{Publication History}

Received by Neurology: Neuroimmunology \& Neuroinflammation August 19, 2021. Accepted in final form December 3, 2021.

\section{Appendix Authors}

\begin{tabular}{lll}
\hline Name & Location & Contribution \\
\hline Jana & Department of Neurology, & Drafting/revision of the \\
Remlinger, & Inselspital, Bern University & manuscript for content, \\
MSc & Hospital and University of & including medical writing for \\
& Bern; Department of & content; major role in the \\
Biomedical Research, and & acquisition of data; study \\
Graduate School for Cellular & concept or design; and \\
and Biomedical Sciences, & analysis or interpretation of \\
& University of Bern, & data \\
Switzerland &
\end{tabular}

\begin{tabular}{lll}
\hline $\begin{array}{l}\text { Adrian } \\
\text { Madarasz, }\end{array}$ & $\begin{array}{l}\text { Department of Neurology, } \\
\text { Inselspital, Bern University } \\
\text { MD }\end{array}$ & $\begin{array}{l}\text { Drafting/revision of the } \\
\text { manuscript for content, } \\
\text { including medical writing for }\end{array}$ \\
& $\begin{array}{l}\text { Bern; Department of } \\
\text { Biomedical Research, and } \\
\text { Graduate School for Cellular }\end{array}$ & $\begin{array}{l}\text { content; major role in the } \\
\text { acquisition of data; study } \\
\text { concept or design; and }\end{array}$ \\
& $\begin{array}{l}\text { and Biomedical Sciences, } \\
\text { University of Bern, }\end{array}$ & $\begin{array}{l}\text { analysis or interpretation of } \\
\text { data }\end{array}$
\end{tabular}

Switzerland

\begin{tabular}{ll}
\hline Kirsten & Department of Neurology, \\
Guse, PhD & Inselspital, Bern University \\
& Hospital and University of \\
& Bern; Department of \\
& Biomedical Research, \\
& University of Bern, \\
& Switzerland
\end{tabular}

\begin{tabular}{ll}
\hline Robert & Department of Neurology, \\
Hoepner, & Inselspital, Bern University \\
MD & Hospital and University of \\
& Bern; Department of \\
& Biomedical Research, \\
& University of Bern, \\
& Switzerland
\end{tabular}

Drafting/revision of the manuscript for content, including medical writing for content; major role in the acquisition of data; analysis or interpretation of data; and additional contributions: methodology

Drafting/revision of the manuscript for content, including medical writing for content; analysis or interpretation of data; and additional contributions: methodology and performance of experiments

\begin{tabular}{ll}
\hline Maud & Department of Neurology, \\
Bagnoud, & Inselspital, Bern University \\
PhD & Hospital and University of \\
& Bern; Department of \\
& Biomedical Research, and \\
& Graduate School for Cellular \\
& and Biomedical Sciences, \\
& University of Bern, \\
& Switzerland
\end{tabular}

\begin{tabular}{ll}
\hline Ivo Meli, & Department of Neurology, \\
MSc & Inselspital, Bern University \\
& Hospital and University of \\
& Bern; Department of \\
& Biomedical Research, \\
& University of Bern, \\
& Switzerland
\end{tabular}

Moritz Feil, Department of

Ophthalmology, Inselspital, Bern University Hospital and including medical writing for University of Bern, content, and additional Switzerland

\begin{tabular}{ll}
\hline Moritz Feil, & Department of \\
MD & Ophthalmology, Inselspital, \\
& Bern University Hospital and \\
& University of Bern, \\
& Switzerland
\end{tabular}

Drafting/revision of the manuscript for content including medical writing for content; analysis or interpretation of data; and additional contributions: methodology and performance of experiments

Drafting/revision of the manuscript for content, including medical writing for content; major role in the acquisition of data; and additional contributions: methodology

Drafting/revision of the contributions: methodology and performance of experiments

\begin{tabular}{|c|c|c|}
\hline $\begin{array}{l}\text { Mathias } \\
\text { Abegg, MD, } \\
\text { PhD }\end{array}$ & $\begin{array}{l}\text { Department of } \\
\text { Ophthalmology, Inselspital, } \\
\text { Bern University Hospital and } \\
\text { University of Bern, } \\
\text { Switzerland }\end{array}$ & $\begin{array}{l}\text { Drafting/revision of the } \\
\text { manuscript for content, } \\
\text { including medical writing for } \\
\text { content, and analysis or } \\
\text { interpretation of data }\end{array}$ \\
\hline
\end{tabular}

Appendix (continued)

\begin{tabular}{lll}
\hline Name & Location & Contribution \\
\hline $\begin{array}{ll}\text { Christopher } \\
\text { Linington, }\end{array}$ & $\begin{array}{l}\text { Institute of Infection, } \\
\text { Immunity and Inflammation, }\end{array}$ & $\begin{array}{l}\text { Drafting/revision of the } \\
\text { manuscript for content, } \\
\text { including medical writing for } \\
\text { University of Glasgow, } \\
\text { United Kingdom }\end{array}$ \\
& $\begin{array}{l}\text { content; analysis or } \\
\text { interpretation of data; and } \\
\text { additional contributions: } \\
\text { contribution of reagents/ } \\
\text { materials/analysis tools/ } \\
\text { infrastructure }\end{array}$ \\
&
\end{tabular}

Anthony UCB Pharma, Slough, United Drafting/revision of the

Shock, PhD Kingdom manuscript for content, including medical writing for content; analysis or interpretation of data; and additional contributions: contribution of reagents/ materials/analysis tools/ infrastructure

\begin{tabular}{ll}
\hline Babak & UCB Pharma, Monheim-am- \\
Boroojerdi, & Rhein, Germany \\
MD, PhD &
\end{tabular}

Drafting/revision of the manuscript for content, including medical writing for content; study concept or design; and additional contributions: contribution of reagents/materials/ analysis tools/infrastructure

\begin{tabular}{lll}
\hline $\begin{array}{l}\text { Peter } \\
\text { Kiessling, }\end{array}$ & RCB Pharma, Monheim-am- & Drafting/revision of the \\
PhD & manuscript for content, \\
& including medical writing for \\
& content; study concept or \\
& design; and additional \\
& contributions: contribution \\
& of reagents/materials/ \\
& analysis tools/infrastructure
\end{tabular}

Bryan UCB Pharma, Slough, United Drafting/revision of the

Smith, PhD Kingdom manuscript for content, including medical writing for content; study concept or design; and additional contributions: contribution of reagents/materials/ analysis tools/infrastructure

Volker Department of Biomedical Drafting/revision of the

Enzmann, Research, University of Bern; manuscript for content, PhD Department of including medical writing for Ophthalmology, Inselspital, content; analysis or Bern University Hospital and interpretation of data; and University of Bern, additional contributions: Switzerland methodology and contribution of reagents/ materials/analysis tools/ infrastructure

\begin{tabular}{|c|c|c|}
\hline $\begin{array}{l}\text { Andrew } \\
\text { Chan, MD }\end{array}$ & $\begin{array}{l}\text { Department of Neurology, } \\
\text { Inselspital, Bern University } \\
\text { Hospital and University of } \\
\text { Bern; Department of } \\
\text { Biomedical Research, } \\
\text { University of Bern, } \\
\text { Switzerland }\end{array}$ & $\begin{array}{l}\text { Drafting/revision of the } \\
\text { manuscript for content, } \\
\text { including medical writing for } \\
\text { content; analysis or } \\
\text { interpretation of data; and } \\
\text { additional contributions: } \\
\text { methodology and contribution } \\
\text { of reagents/materials/analysis } \\
\text { tools/infrastructure }\end{array}$ \\
\hline $\begin{array}{l}\text { Anke } \\
\text { Salmen, MD }\end{array}$ & $\begin{array}{l}\text { Department of Neurology, } \\
\text { Inselspital, Bern University } \\
\text { Hospital and University of } \\
\text { Bern; Department of } \\
\text { Biomedical Research, } \\
\text { University of Bern, } \\
\text { Switzerland }\end{array}$ & $\begin{array}{l}\text { Drafting/revision of the } \\
\text { manuscript for content, } \\
\text { including medical writing for } \\
\text { content; major role in the } \\
\text { acquisition of data; study } \\
\text { concept or design; and analysis } \\
\text { or interpretation of data }\end{array}$ \\
\hline
\end{tabular}




\section{References}

1. Jarius S, Paul F, Aktas O, et al. MOG encephalomyelitis: international recommendations on diagnosis and antibody testing. J Neuroinflamm. 2018;15(1):134. doi: 10.1186/s12974-018-1144-2

2. Sepúlveda M, Armangue T, Martinez-Hernandez E, et al. Clinical spectrum associated with MOG autoimmunity in adults: significance of sharing rodent MOG epitopes. J Neurol. 2016;263(7):1349-1360. doi:10.1007/s00415-016-8147-7.

3. Dos Passos GR, Oliveira LM, da Costa BK, et al. MOG-IgG-associated optic neuritis, encephalitis, and myelitis: lessons learned from neuromyelitis optica spectrum disorder. Front Neurol. 2018;9:217. doi:10.3389/fneur.2018.00217.

4. Veselaj K, Kamber N, Briner M, et al. Evaluation of diagnostic criteria and red flags of myelin oligodendrocyte glycoprotein encephalomyelitis in a clinical routine cohort. CNS Neurosci Ther. 2021;27(4):426-438. doi:10.1111/cns.13461.

5. Hamid SHM, Whittam D, Mutch K, et al. What proportion of AQP4-IgG-negative NMO spectrum disorder patients are MOG-IgG positive? A cross sectional study of 132 patients. J Neurol. 2017;264(10):2088-2094. doi:10.1007/s00415-017-8596-7.

6. Kitley J, Waters $\mathrm{P}$, Woodhall $\mathrm{M}$, et al. Neuromyelitis optica spectrum disorders with aquaporin-4 and myelin-oligodendrocyte glycoprotein antibodies: a comparative study. JAMA Neurol. 2014;71(3):276-283. doi:10.1001/jamaneurol.2013.5857.

7. Spadaro M, Winklmeier S, Beltran E, et al. Pathogenicity of human antibodies against myelin oligodendrocyte glycoprotein. Ann Neurol. 2018;84(2):315-328. doi:10.1002/ ana.25291.

8. Macrini C, Gerhards R, Winklmeier S, et al. Features of MOG required for recognition by patients with MOG antibody-associated disorders. Brain. 2021;144(8):2375-2389. doi:10.1093/brain/awab105.

9. Akaishi T, Takahashi T, Misu T, et al. Difference in the source of anti-AQP4-IgG and anti-MOG-IgG antibodies in CSF in patients with neuromyelitis optica spectrum disorder. Neurology. 2021;97(1):e1-e12. doi:10.1212/wnl.0000000000012175.

10. Chen JJ, Flanagan EP, Bhatti MT, et al. Steroid-sparing maintenance immunotherapy for MOG-IgG associated disorder. Neurology. 2020;95(2):e111-e120. doi:10.1212/ WNL.0000000000009758.

11. Whittam DH, Cobo-Calvo A, Lopez-Chiriboga AS, et al. Treatment of MOG-IgGassociated disorder with rituximab: an international study of 121 patients. Mult Scler Relat Disord. 2020;44:102251. doi:10.1016/j.msard.2020.102251.

12. Cree BAC, Bennett JL, Kim HJ, et al. Inebilizumab for the treatment of neuromyelitis optica spectrum disorder (N-MOmentum): a double-blind, randomised placebocontrolled phase 2/3 trial. Lancet. 2019;394(10206):1352-1363. doi:10.1016/S01406736(19)31817-3.

13. Pittock SJ, Berthele A, Fujihara K, et al. Eculizumab in aquaporin-4-positive neuromyelitis optica spectrum disorder. N Engl J Med. 2019;381(7):614-625. doi:10.1056/ NEJMoa1900866.

14. Traboulsee A, Greenberg BM, Bennett JL, et al. Safety and efficacy of satralizumab monotherapy in neuromyelitis optica spectrum disorder: a randomised, double-blind, multicentre, placebo-controlled phase 3 trial. Lancet Neurol. 2020;19(5):402-412. doi: 10.1016/S1474-4422(20)30078-8.

15. Yamamura T, Kleiter I, Fujihara K, et al. Trial of satralizumab in neuromyelitis optica spectrum disorder. $N$ Engl J Med. 2019;381(22):2114-2124. doi:10.1056/ NEJMoa1901747.

16. Marignier R, Hacohen Y, Cobo-Calvo A, et al. Myelin-oligodendrocyte glycoprotein antibody-associated disease. Lancet Neurol. 2021;20(9):762-772. doi:10.1016/s14744422(21)00218-0.

17. Roopenian DC, Akilesh S. FcRn: the neonatal Fc receptor comes of age. Nat Rev Immunol. 2007;7(9):715-725. doi:10.1038/nri2155

18. Lunemann JD, Nimmerjahn F, Dalakas MC. Intravenous immunoglobulin in neurology—mode of action and clinical efficacy. Nat Rev Neurol. 2015;11(2):80-89. doi:10.1038/nrneurol.2014.253

19. Challa DK, Bussmeyer U, Khan T, et al. Autoantibody depletion ameliorates disease in murine experimental autoimmune encephalomyelitis. mAbs. 2013;5(5):655-659. doi: 10.4161/mabs.25439.

20. Patel DA, Puig-Canto A, Challa DK, Perez Montoyo H, Ober RJ, Ward ES. Neonata Fc receptor blockade by $\mathrm{Fc}$ engineering ameliorates arthritis in a murine model J Immunol. 2011;187(2):1015-1022. doi:10.4049/jimmunol.1003780.

21. Sun W, Khare P, Wang X, et al. Selective depletion of antigen-specific antibodies fo the treatment of demyelinating disease. Mol Ther. 2021;29(3):1312-1323. doi: 10.1016/j.ymthe.2020.11.017.

22. Newland AC, Sanchez-Gonzalez B, Rejto L, et al. Phase 2 study of efgartigimod, a novel $\mathrm{FcRn}$ antagonist, in adult patients with primary immune thrombocytopenia. Am J Hematol. 2020;95(2):178-187. doi:10.1002/ajh.25680.

23. Howard JF Jr, Bril V, Vu T, et al. Safety, efficacy, and tolerability of efgartigimod in patients with generalised myasthenia gravis (ADAPT): a multicentre, randomised, placebo-controlled, phase 3 trial. Lancet Neurol. 2021;20(7):526-536. doi:10.1016/ s1474-4422(21)00159-9.

24. Bril V, Benatar M, Andersen H, et al. Efficacy and safety of rozanolixizumab in moderate to severe generalized myasthenia gravis: a phase 2 randomized control trial. Neurology. 2021;96(6):e853-e865. doi:10.1212/WNL.0000000000011108.

25. Kiessling P, Lledo-Garcia R, Watanabe $\mathrm{S}$, et al. The FcRn inhibitor rozanolixizumab reduces human serum IgG concentration: a randomized phase 1 study. Sci Transl Med. 2017;9(414):eaan1208. doi:10.1126/scitranslmed.aan1208.

26. Robak T, Kazmierczak M, Jarque I, et al. Phase 2 multiple-dose study of an FcRn inhibitor, rozanolixizumab, in patients with primary immune thrombocytopenia. Blood Adv. 2020;4(17):4136-4146. doi:10.1182/bloodadvances.2020002003.

27. Smith B, Kiessling A, Lledo-Garcia R, et al. Generation and characterization of a high affinity anti-human $\mathrm{FcRn}$ antibody, rozanolixizumab, and the effects of different molecular formats on the reduction of plasma IgG concentration. mAbs. 2018;10(7): 1111-1130. doi:10.1080/19420862.2018.1505464.

28. Ling LE, Hillson JL, Tiessen RG, et al. M281, an anti-FcRn antibody: pharmacodynamics, pharmacokinetics, and safety across the full range of IgG reduction in a firstin-human study. Clin Pharmacol Ther. 2019;105(4):1031-1039. doi:10.1002/ cpt.1276.

29. Smith B, Christodoulou L, Clargo A, et al. Generation of two high affinity anti-mouse FcRn antibodies: inhibition of IgG recycling in wild type mice and effect in a mouse model of immune thrombocytopenia. Int Immunopharmacol. 2019;66:362-365. doi: 10.1016/j.intimp.2018.11.040

30. Linker RA, Mäurer M, Gaupp S, et al. CNTF is a major protective factor in demyelinating CNS disease: a neurotrophic cytokine as modulator in neuroinflammation. Nat Med. 2002;8(6):620-624. doi:10.1038/nm0602-620.

31. Hoepner R, Bagnoud M, Pistor M, et al. Vitamin D increases glucocorticoid efficacy via inhibition of mTORC1 in experimental models of multiple sclerosis. Acta Neuropathol. 2019;138(3):443-456. doi:10.1007/s00401-019-02018-8.

32. Lühder F, Kebir H, Odoardi F, et al. Laquinimod enhances central nervous system barrier functions. Neurobiol Dis. 2017;102:60-69. doi:10.1016/j.nbd.2017.02.002.

33. Prusky GT, West PW, Douglas RM. Behavioral assessment of visual acuity in mice and rats. Vis Res. 2000;40(16):2201-2209. doi:10.1016/s0042-6989(00)00081-x.

34. Benkner B, Mutter M, Ecke G, Münch TA. Characterizing visual performance in mice: an objective and automated system based on the optokinetic reflex. Behav Neurosci. 2013;127(5):788-796. doi:10.1037/a0033944.

35. Collewijn H. Optokinetic eye movements in the rabbit: input-output relations. Vis Res. 1969;9(1):117-132. doi:10.1016/0042-6989(69)90035-2.

36. Kretschmer F, Tariq M, Chatila W, Wu B, Badea TC. Comparison of optomotor and optokinetic reflexes in mice. J Neurophysiol. 2017;118(1):300-316. doi:10.1152/ jn.00055.2017.

37. Atmaca-Sonmez P, Li Y, Yamauchi Y, et al. Systemically transferred hematopoietic stem cells home to the subretinal space and express RPE-65 in a mouse model of retinal pigment epithelium damage. Exp Eye Res. 2006;83(5):1295-1302. doi: $10.1016 /$ j.exer.2006.07.013

38. Linington C, Bradl M, Lassmann H, Brunner C, Vass K. Augmentation of demyelination in rat acute allergic encephalomyelitis by circulating mouse monoclonal antibodies directed against a myelin/oligodendrocyte glycoprotein. Am I Pathol. 1988;130(3):443-454.

39. Kasprick A, Hofrichter M, Smith B, et al. Treatment with anti-neonatal $\mathrm{F}_{\mathrm{c}}$ receptor $(\mathrm{FcRn})$ antibody ameliorates experimental epidermolysis bullosa acquisita in mice. $\mathrm{Br}$ J Pharmacol. 2020;177(10):2381-2392. doi:10.1111/bph.14986.

40. Cruz-Herranz A, Dietrich M, Hilla AM, et al. Monitoring retinal changes with optical coherence tomography predicts neuronal loss in experimental autoimmune encephalomyelitis. J Neuroinflamm. 2019;16(1):203. doi:10.1186/s12974-019-1583-4.

41. Manogaran P, Samardzija M, Schad AN, et al. Retinal pathology in experimental optic neuritis is characterized by retrograde degeneration and gliosis. Acta Neuropathol Commun. 2019;7(1):116. doi:10.1186/s40478-019-0768-5.

42. Tokashiki N, Nishiguchi KM, Fujita K, Sato K, Nakagawa Y, Nakazawa T. Reliable detection of low visual acuity in mice with pattern visually evoked potentials. Sci Rep. 2018;8(1):15948. doi:10.1038/s41598-018-34413-8.

43. Horstmann L, Schmid H, Heinen AP, Kurschus FC, Dick HB, Joachim SC. Inflammatory demyelination induces glia alterations and ganglion cell loss in the retin of an experimental autoimmune encephalomyelitis model. J Neuroinflamm. 2013;10: 120. doi:10.1186/1742-2094-10-120.

44. Baker K, Rath T, Pyzik M, Blumberg RS. The role of FcRn in antigen presentation. Front Immunol. 2014;5:408. doi:10.3389/fimmu.2014.00408

45. Ben-Nun A, Kaushansky N, Kawakami N, et al. From classic to spontaneous and humanized models of multiple sclerosis: impact on understanding pathogenesis and drug development. J Autoimmun. 2014;54:33-50. doi:10.1016/j.jaut.2014.06.004 


\section{Neurology \\ Neuroimmunology \& Neuroinflammation}

\section{Antineonatal Fc Receptor Antibody Treatment Ameliorates MOG-IgG-Associated Experimental Autoimmune Encephalomyelitis \\ Jana Remlinger, Adrian Madarasz, Kirsten Guse, et al. \\ Neurol Neuroimmunol Neuroinflamm 2022;9; \\ DOI 10.1212/NXI.0000000000001134}

This information is current as of January 13, 2022

Updated Information \&

Services

References

Subspecialty Collections

Permissions \& Licensing

Reprints including high resolution figures, can be found at:

http://nn.neurology.org/content/9/2/e1134.full.html

This article cites 45 articles, 3 of which you can access for free at: http://nn.neurology.org/content/9/2/e1134.full.html\#\#ref-list-1

This article, along with others on similar topics, appears in the

following collection(s):

Optic nerve

http://nn.neurology.org//cgi/collection/optic_nerve

Retina

http://nn.neurology.org//cgi/collection/retina

Information about reproducing this article in parts (figures,tables) or in its entirety can be found online at:

http://nn.neurology.org/misc/about.xhtml\#permissions

Information about ordering reprints can be found online: http://nn.neurology.org/misc/addir.xhtml\#reprintsus

Neurol Neuroimmunol Neuroinflamm is an official journal of the American Academy of Neurology.

Published since April 2014, it is an open-access, online-only, continuous publication journal. Copyright

Copyright (C) 2022 The Author(s). Published by Wolters Kluwer Health, Inc. on behalf of the American

Academy of Neurology.. All rights reserved. Online ISSN: 2332-7812.

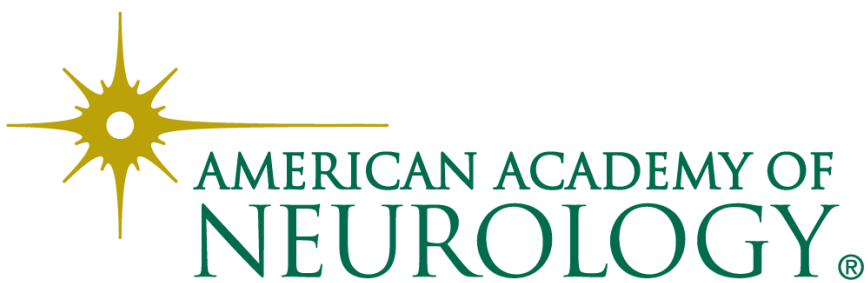

